\title{
PODER POLÍTICO E RELAÇÕES DE PARENTESCO NO MUNICÍPIO DE LONDRINA - PARANÁ ${ }^{1}$
}

\author{
Carla Andréia Alves da Silva ${ }^{2}$
}

- Enviado em 22/09/2015

- Aprovado em 30/10/2015

\begin{abstract}
RESUMO
O nepotismo é um fenômeno latente na política brasileira, ocorrendo desde as regiões mais antigas e tradicionais, até nos locais de colonização mais recente, como é o caso do município de Londrina, Estado do Paraná, no qual em apenas 80 anos de história já se formaram redes de poder político e parentesco. O objeto deste trabalho são as relações de poder político e parentesco formadas em Londrina, no intuito de verificar se estas relações ocorrem também em cidades mais novas, não pertencentes ao chamado "Paraná Tradicional", ao que ficou demonstrado que o tempo, neste caso, não é um fator determinante para a formação das teias de nepotismo, mas sim a existência de capitais político e econômico e relações que garantam capital social para entrar, manter-se e reproduzir-se com os seus familiares na política brasileira. Ademais, a colocação de familiares em cargos estratégicos é uma forma de garantir longevidade no poder, já que desta forma pode-se ter o controle inclusive das instituições responsáveis pela fiscalização das atividades de estado e de governo. Em Londrina temos uma família mais expressiva, sendo o maior grupo que ainda mantém-se no poder local, espraiando-se por outros poderes e esferas de governo. Trata-se da família Belinati, iniciada na atividade política com Antonio Casemiro Belinati, um político outsider que ao longo de sua história transformou-se em estabelecido; o grupo Belinati já possui mais de quinze membros da família que, juntos, ocuparam mais de quarenta cargos públicos, sejam eles eletivos, comissionados ou concursados. Além desta família central, pudemos localizar outras dezesseis famílias de atuação política na cidade, muitas delas com projeção em âmbito estadual e federal. São elas: famílias Richa, Dias, Hosken de Novaes/Castaldi, Rocha Loures, Carvalho/Canizares, Corrêa, Janene/Jannani/Jenani, Del Ciel, Gabardo, Leite Chaves, Maculan, Cesáreo Pereira, Stamm, Scaff, Canziani e Caldarelli. Como método, utilizamo-nos da sociologia das biografias, analisando a trajetória destas famílias, verificando suas movimentações no espaço social, lançando mão das categorias de campo, habitus e capitais, de Pierre Bourdieu.
\end{abstract}

Palavras-chave: Nepotismo. Poder Político. Famílias. Londrina-Paraná.

\section{INTRODUÇÃO}

Apesar de relativamente nova, a cidade de Londrina já teve nos seus 81 anos de existência tempo suficiente para a formação de redes familiares ocupando o poder político local, espraiando-se para as esferas estadual e federal. Algumas famílias com atuações mais discretas, com dois ou três membros no poder ao

\footnotetext{
1 Dissertação defendida em 09 de abril de 2015. Versão completa disponível na Biblioteca Digital da UFPR http://dspace.c3sl.ufpr.br:8080/dspace/handle/1884/38289.

2 Graduada em Serviço Social pela Universidade Estadual de Londrina. Mestre em Sociologia pela Universidade Federal do Paraná. Assistente Social do Governo do Estado do Paraná, com atuação na área de Direitos Humanos de Crianças e Adolescentes. Endereço eletrônico: carlaalves@onda.com.br
} 
longo dos anos, outras com mais de dez ou quinze pessoas ocupando cargos públicos de maior ou menor influência dentro da organização estatal.

Com sua colonização iniciada nos anos de 1920 pelos ingleses da Companhia de Terras do Norte do Paraná - CTNP, Londrina foi oficialmente fundada em 1934 e a partir de então teve a sua vida política ligada ao capital cafeeiro e ao agronegócio, com influência da Sociedade Rural do Paraná - SRP e da Associação Comercial e Industrial de Londrina - ACIL. Grande parte das famílias pesquisadas tiveram alguma ligação com estas instituições e em alguns casos, vários familiares ocupando a presidência delas ao longo dos anos.

O curso da história local foi alterado a partir da chamada "geada negra" de $1975^{3}$. Com a queda do café houve um grande processo migratório do campo para a cidade e com esta migração em massa vieram o desemprego no meio urbano, ausência de moradias, surgimento de bolsões de pobreza, dentre outros. Cenário perfeito para o surgimento de políticos chamados outsiders, que se colocam no lugar e no momento certo da cena política para conquistar espaço, sem ter um histórico na política local: um político novo que surge como o "salvador da pátria". Neste sentido, na década de 1970, o discurso político elitizado vindo dos representantes do capital cafeeiro e dos profissionais liberais e empresários bem sucedidos já não convencia mais os londrinenses, que viviam dias difíceis na economia local. A população buscava "o novo", alguém que representasse os seus reais interesses naquele momento e neste contexto tivemos o ingresso na vida política da principal família no poder em Londrina.

Nosso objetivo aqui é tratar da trajetória da família Belinati, mais extensamente, e de outras dezesseis famílias, analisando os capitais (social, cultural e político) e os fatores que os levaram a chegar e manter-se no poder em Londrina e no Estado do Paraná. Estas trajetórias, se pautarmo-nos em Bourdieu (2011), podem ser definidas como os deslocamentos dos indivíduos no espaço social. Complementando a noção de trajetórias, Montagner (2007, p.254), inspirado em Bourdieu, afirma que "uma trajetória é a objetivação das relações entre os agentes e as forças presentes no campo." Outro conceito aqui trabalhado é o de família. Para Bourdieu (2011), a família tem papel determinante na reprodução da estrutura e do espaço social e é a responsável por acumular e transmitir privilégios aos seus. Privilégios estes que são de natureza econômica, cultural e simbólica.

\section{Família Belinati}

O ingresso de Antonio Casemiro Belinati no cenário político londrinense teve início na década de 1960. Nascido em Campo Grande-MS, Belinati chegou em Londrina aos cinco anos de idade. Sua mãe era dona de casa e o pai ferroviário, funcionário da extinta Rede Ferroviária Federal Sociedade Anônima RFFSA. Belinati teve sua ascensão favorecida pelo rádio; aos 18 anos, começou a trabalhar na Rádio Londrina auxiliando a equipe da rádio em diversas atividades, trabalhando junto de Otássio Pereira, também radialista e vereador na cidade. Durante esta convivência, Belinati diz ter aprendido no cotidiano a ser

\footnotetext{
${ }^{3}$ Segundo Tomazi (1997) a derrocada final do café deu-se com a geada de 1975, a qual o mesmo nomina como a "pá de cal" na cafeicultura paranaense. Ocorrida em 18 de julho de 1975, a geada negra assolou todo o Estado do Paraná, com frio intenso e condições atmosféricas que fizeram com que as plantas tivessem a sua parte interna congelada, matando os cafezais do Norte do Estado.
} 
radialista, até surgir uma oportunidade para que entrasse no ar, conforme relato do próprio em entrevista concedida ao jornalista Osmani Ferreira Costa:

O Otássio comandava o programa Ronda dos Municípios, transmitido ao vivo a cada domingo de uma cidade diferente da região. Naquela semana, o Otássio me convidou para ir junto com a equipe para Cornélio Procópio. Não sei por qual motivo, o locutor oficial dos reclames - as propagandas da época - não pôde viajar com a gente. Foi a minha primeira oportunidade. O Otássio pediu para eu narrar, nos intervalos, todas as mensagens publicitárias. Nervoso, cometi um grave erro: li Mortandela Diana, em vez de mortadela. Na segunda-feira, o gerente comercial da emissora chamou o Otássio e me proibiu de voltar ao ar, dizendo que eu tinha péssima voz, dicção horrível e lido errado o nome do principal patrocinador. Foi assim, de maneira desastrosa, a minha estreia no rádio. ( COSTA, 2005, p. 181-182)

O fato acima narrado ocorreu em 1961. Somente em 1967 Belinati teve seu primeiro programa na Rádio Londrina. Popular, Belinati ingressou no mesmo partido (MDB) do seu "padrinho" no rádio e na política, Otássio Pereira. Otássio, por sua vez, foi o primeiro radialista na história de Londrina a conquistar um cargo eletivo, no ano de 1959.

A partir deste primeiro programa na Rádio Londrina, em que pese estivesse no ar por apenas trinta minutos ao dia, Belinati ganhou popularidade e, em 1968, foi eleito vereador pela primeira vez, sendo o candidato mais votado para o Legislativo Municipal naquele pleito. Apenas dois anos depois, elegeu-se deputado estadual com muita facilidade, sendo o mais votado do MDB naquele ano. Nas eleições subsequentes, em 1972, Belinati candidatou-se ao cargo de prefeito, tendo sido derrotado por José Richa, também do MDB. Após esta derrota, Belinati ganhou um programa de variedades com maior visibilidade no rádio, de nome “A Voz do Povo”. Segundo COSTA (2005, p.197), os programas desta natureza (variedades), normalmente possuem linguagem próxima e amiga dos ouvintes e severa e enérgica quando faz críticas a alguém; os radialistas deste gênero normalmente comentam fatos da vida cotidiana, envolvendo política, economia, segurança, etc. e adotam sempre uma postura que varia entre "sentimentalista pessoal", "crítico social" e de "engajamento politico-ideológico", pairando também pelo assistencialismo. Durante o período, Belinati chegou a fazer curtas incursões na televisão, como repórter.

Em que pese a derrota de Belinati para o cargo máximo do executivo municipal, as eleições de 1972 marcam a entrada do segundo membro da família Belinati na política, alçando um cargo eletivo na "carona" da popularidade de Antonio Belinati. Waldmir Belinati elegeu-se vereador pelo MDB, sendo na ocasião o vereador que recebeu o maior número de votos. Waldmir Belinati é irmão de Antônio Belinati e à época era estudante de medicina na UEL e professor. Waldmir prosseguiu na carreira política elegendo-se vereador pela segunda vez pelo MDB em 1976. Em 1978 foi eleito deputado federal também pelo MDB. Além dos cargos eletivos alçados, Waldmir protagonizou na família Belinati o primeiro caso de nepotismo direto. Oliveira (2012, p. 03) esclarece que na sociologia política, nepotismo "é a relação entre parentesco e Estado", é a ocupação de cargos públicos por pessoas de uma rede de parentesco. Waldmir exerceu em Londrina o cargo de Secretário Municipal de Saúde e Promoção Social, cargo comissionado, nomeado por Belinati enquanto prefeito da cidade. Em mais um caso de nepotismo, Waldmir ocupou durante o governo de 
Jaime Lerner, no poder executivo estadual, no qual sua cunhada Emília Salles Belinatti foi vice-governadora, o cargo de superintendente do Instituto de Previdência e Assistência aos Servidores do Estado do Paraná IPE. Após estas incursões, Waldmir retornou à Londrina onde exerce até os dias atuais a profissão de médico.

Retomando a trajetória de Antonio Belinati, em 1974 obteve mais um êxito eleitoral, alçando vaga na Câmara Federal, sendo o segundo deputado mais votado do MDB do Paraná. A consolidação da força de Belinati deu-se em 1976, após a geada negra que citamos no início deste artigo, quando conseguiu eleger-se prefeito de Londrina. Belinati aproveitou-se do contexto de descrença da população londrinense naqueles que ocupavam o poder até então, focando no fato de a então elite dirigente não ser capaz de captar e atender as demandas sociais emergentes vindas do processo de crise da cultura do café.

A suposta renovação com a eleição de Belinati foi algo tão mítico na política londrinense daquele período, que na galeria oficial de prefeitos de Londrina, disponível na Prefeitura Municipal, podemos encontrar a seguinte menção a esta eleição: "Pela primeira vez os londrinenses viam chegar à Prefeitura um politico recrutado dos segmentos populares, de baixa escolaridade e que se ocupava do radialismo", fazendo possivelmente menção aos anos anteriores no qual o domínio da Companhia de Terras do Norte do Paraná e depois da Sociedade Rural do Paraná e da Associação Comercial e Industrial de Londrina era latente na política municipal, através da eleição de profissionais liberais e agropecuaristas.

No primeiro mandato como prefeito de Londrina (1977-1982) Belinati tornou-se muito popular e adotou uma postura considerada pelos seus oponentes como populista. A marca desta primeira gestão municipal foram as moradias populares e quiçá, talvez esta seja até hoje a maior marca a qual o nome de Antonio Belinati está ligado. Isto se deve à quantidade de casas em conjuntos habitacionais construídas e entregues à população londrinense. Conforme dados da Cohab-LD, foram entregues neste período cerca de 15 mil casas populares no local que ainda hoje é conhecido como "Cinco Conjuntos".

Ainda que Belinati tenha surgido como a figura do outsider e tenha se consolidado como um político populista, este conseguiu facilmente transitar pela elite londrinense, “[...] isto porque as lideranças políticas dirigentes locais souberam incorporar o radialista/populista ao seu grupo [...]." (CERVI, 2002, p. 50). Se pensarmos pela linha dos teóricos elitistas ${ }^{4}$, para ingressar na elite dirigente, pertencer a uma ou outra classe social não é o critério principal, mas possuir capacidades e atributos pessoais é fundamental. $\mathrm{O}$ carisma de Belinati perante a massa certamente era um atributo importante, o qual foi rapidamente incorporado à elite política local. A incorporação de Belinati à elite local da época fica provada pela composição do primeiro escalão municipal, quase em sua íntegra composta por profissionais liberais, empresários bem sucedidos da região, agropecuaristas e intelectuais das fileiras da UEL. Em que pese Belinati representasse a renovação, o perfil da elite dirigente local manteve-se o mesmo em seu governo.

Quanto à inserção de familiares de Belinati ocupando cargos estratégicos nesta primeira gestão municipal pudemos encontrar apenas a situação de sua esposa, Emília de Sales Belinati, a qual ocupou a

\footnotetext{
${ }^{4}$ Temos como principais referências da Teoria das Elites os autores europeus Gaetano Mosca (1858-1941), Vilfredo Pareto (1848-1923) e Robert Michels (1876-1936).
} 
presidência da Associação de Proteção à Maternidade e à Infância - $\mathrm{APMI}^{5}$, reforçando assim uma vez mais a lógica do "primeiro-damismo", no qual se nomeia a esposa do chefe do Poder Executivo, chamada na nossa cultura de primeira-dama, para chefiar a área da assistência social ou da infância e juventude, com práticas assistencialistas, vinculando o casal a imagem de caridosos, benevolentes e cuidadores dos "pobres".

Em 1982, Belinati migrou de partido, afastando-se do cargo de prefeito antes do término do mandato, no intuito de candidatar-se ao Governo do Estado. Migrou para o PDS, o qual abrigou grande parte dos políticos da ARENA. A candidatura de Belinati ao executivo estadual foi inviabilizada dentro do partido e este concorreu a uma vaga para deputado estadual, ficando na suplência. Apesar da votação inexpressiva, Belinati permaneceu com suas atividades no rádio e acabou assumindo mais tarde a vaga na ALEP devido ao falecimento de um deputado. Ainda nas eleições gerais de 1982, a família Belinati emplaca mais um "descendente" político direto em cargo eletivo: o irmão de Belinati, Roberval Casemiro Belinati, foi o segundo vereador mais votado do PDS no município.

Roberval havia sido radialista e repórter na Rádio Londrina e na Rádio Cruzeiro do Sul. Atuou no Novo Jornal e na Folha de Londrina, o jornal mais relevante da cidade até os dias atuais. Trabalhou também como Assessor Parlamentar de deputados do PDS, inclusive do próprio irmão, em Brasília-DF. Formou-se em direito, atuando na advocacia em Brasília e em Londrina, acumulada ao cargo de diretor geral da Rádio Clube de Londrina no início da década de 1980. Após ter sido vereador, Roberval não incursionou mais na vida política londrinense; foi aprovado em concurso para o cargo de Juiz Substituto no Poder Judiciário do Estado de Mato Grosso do Sul, onde atuou no final da década de 1980. Em 1992 assumiu como Juiz Titular do Tribunal de Justiça do Distrito Federal e dos Territórios, onde atualmente é Desembargador.

Em 1988 Antonio Belinati elegeu-se novamente prefeito. Na segunda gestão de Antonio Belinati como prefeito (1989-1992), vemos mais uma vez nenhuma renovação na elite dirigente local. Este fato é natural se pensarmos que já se passaram quase duas décadas da inserção de Belinati na política, tempo suficiente para sua integração à elite local. Nestas mesmas eleições de 1988, a família Belinati consegue ter eleito o seu quarto "filho", José Belinati Filho, irmão de Antonio Belinati. José Filho elegeu-se pelo PDT, sendo naquele pleito o terceiro mais votado. José Belinati Filho era funcionário público municipal e, como veremos mais adiante, teve também seu filho eleito com vereador em Londrina.

Nas eleições gerais de 1990, Emília Salles Belinati, esposa de Antonio Casemiro Belinati, é eleita ao seu primeiro cargo, como deputada estadual, pelo PDT, sendo a única mulher da $12^{\mathrm{a}}$ Legislatura (19911994). Emília era filha de agricultores e nasceu em Londrina. Segundo entrevista dela concedida a Enéias Faria e Sylvio Sebastiani (1997), ela foi jogadora da seleção paranaense de basquetebol na década de 1960 e em 1974 formou-se no curso de Educação Física. Emília e Antonio Belinati se conheceram em 1965 de forma bastante peculiar: ao levar seu pai a um famoso neurologista de Londrina, Belinati encantou-se pela secretária do médico.

\footnotetext{
${ }^{5}$ Embora as APMIs não sejam instituições governamentais, acabam funcionando atreladas diretamente aos governos, ou vinculadas à instituições governamentais específicas.
} 
Em 1994, Emília, no PTB, foi convidada pelo ex-prefeito de Curitiba, Jaime Lerner (PDT), para compor chapa com ele, concorrendo ao cargo de vice-governadora, unindo assim a força da família Belinati no Norte do Paraná à popularidade de Jaime Lerner na capital e região metropolitana. Jaime Lerner e Emília saíram vencedores do pleito já no primeiro turno, totalizando 54,85\% dos votos válidos. Em 1998, Emília novamente disputou o governo do Estado como vice de Jaime Lerner, agora no PFL, eleitos novamente no primeiro turno com $52,21 \%$ dos votos válidos.

Segundo informações da imprensa, Emília e Antonio Belinati divorciaram-se no ano de 2006. Também em 2006 Emília Belinati concorreu ao cargo de deputada federal pelo PFL, ficando na suplência. Após esta derrota, aliou-se ao grupo do então prefeito de Curitiba, Beto Richa, sendo nomeada em abril de 2007 para um cargo de direção no Instituto Curitiba de Saúde - ICS. Emília permaneceu no cargo até o ano de 2010, quando nas eleições gerais disputou o cargo de deputada estadual, pelo PSB. Os resultados desta eleição mostram uma Emília já mais enfraquecida politicamente perante a população paranaense, em especial Londrina, seu reduto eleitoral, já que ficou apenas com a suplênia. Em agosto de 2013, conforme amplamente noticiado na imprensa paranaense, Emília Belinati foi eleita pelo Conselho Administrativo da SANEPAR para ocupar o cargo de Diretora Comercial, assumindo o lugar do seu filho Antonio Carlos, o qual retornou ao cargo no início de 2015.

Retomando mais uma vez a história do protagonista da família Belinati, Antonio Casemiro, nas eleições municipais de 1992 não pleiteou nenhum cargo, pois estava encerrando o seu segundo mandato como prefeito e naquele período a reeleição ainda não era permitida no Brasil. Neste pleito, apenas o seu irmão, José Belinati Filho, candidatou-se a vereador pelo PDT e foi eleito. Nas eleições de 1994, Antonio Casemiro candidatou-se pelo PDT ao cargo de deputado estadual, obtendo êxito, assumindo uma cadeira na Assembleia Legislativa do Paraná.

Nas eleições municipais de 1996, Belinati obtém o seu terceiro mandato como prefeito de Londrina. Apesar da vitória de Belinati para ocupar a chefia do Poder Executivo municipal, as eleições de 1996 não foram tão vantajosas para seus parentes no legislativo municipal. Sua filha, Cintya Salles Belinati, candidata ao cargo de vereadora pelo PST obteve votação expressiva, mas não o suficiente para eleger-se em sua legenda. Já o irmão do patriarca Belinati, José Belinati Filho, candidato pelo PDT, obteve 1759 votos, ficando na suplência, assumindo a vaga durante no decorrer daquela legislatura.

Sobre Cintya Belinati, embora não tenha tido sucesso em cargos eletivos, esta ocupou cargo comissionado desde o ano de 2007 na ALEP, atuando na coordenação do cerimonial da casa. Cintya foi demitida em 2013 visando a não ter problemas com a regulamentação antinepotismo, pois seu irmão, Antonio Carlos Salles Belinati, havia assumido vaga na casa. A estada de Cyntia na ALEP foi conturbada, pois seu nome figurou na lista dos 72 servidores que a mesa diretora da Assembleia omitiu da lista oficial de funcionários, conforme amplamente divulgado pela imprensa através da série investigativa "Diários Secretos" produzida pelo Grupo RPC - Gazeta do Povo.

Durante o terceiro mandato de Belinati como prefeito, apesar das ações e obras de caráter populistas, Belinati sofreu forte comoção popular contrária a ele quando em 1998 vendeu 45\% das ações da 
maior empresa pública do município, a companhia de telefonia SERCOMTEL. Este terminou antes do seu tempo, mas consagrou a aliança de Belinati com a classe dominante londrinense, incluindo nos cargos de primeiro escalão, além dos profissionais liberais bem sucedidos, membros fortes do empresariado local e políticos ascendentes do município.

Em mais dois casos de nepotismo, Antonio Carlos Salles Belinati (filho de Belinati e Emília) ocupou o cargo de presidente da COMURB e Gino Azzolini Neto, o cargo de Secretário Geral. Gino Azzolini é advogado e ex-vereador no município de Cornélio Procópio-PR, foi Secretário de Estado de Administração na gestão de Álvaro Dias e diretor administrativo da COPEL no primeiro mandato de Roberto Requião como governador. Gino é casado com a sobrinha de Antonio Casemiro Belinati, Geysa Belinati Guazzi Azzolini, a qual é filha da irmã de Belinati, Maria Aparecida Casimiro Belinati Guazzi. Maria Aparecida, por sua vez, também é mãe de Dante Belinati Guazzi, proprietário da construtora e empreiteira de obras públicas Protenge Engenharia, que atualmente executa grande parte das obras do programa federal Minha Casa, Minha Vida, em Londrina.

No pleito de 1998, pela primeira vez o filho de Antonio Casemiro e Emília Salles Belinati, Antonio Carlos Salles Belinati, pleiteia uma vaga de deputado estadual, pelo PSB, obtendo êxito. Neste mesmo pleito, Jaime Lerner e Emília Belinati reelegeram-se para o Governo do Estado do Paraná. Ambos tiveram total apoio de Belinati, tendo a máquina do Estado e da Prefeitura Municipal de Londrina em favor da campanha.

Em fevereiro de 1999 foi iniciada uma série de investigações por parte do Ministério Público do Estado do Paraná na Prefeitura Municipal de Londrina. Os escândalos envolvendo a família Belinati em Londrina começaram com o caso que ficou intitulado "AMA/COMURB", que mais tarde culminou na cassação de Belinati pela Câmara de Vereadores em sessão histórica, no ano 2000. Não abordaremos estes fatos neste artigo, uma vez que nosso foco aqui é apenas analisar as relações de poder político e parentesco na ocupação de cargos públicos pela família Belinati. A única coisa que interessa-nos aqui ressaltar é que a pessoa apontada pelas investigações como sendo um dos principais articuladores do esquema conhecido como "Beligate", foi Gino Azzolini Neto, seu "sobrinho" (esposo de sua sobrinha).

Como a fênix, ave mitológica que se refaz a partir das suas próprias cinzas e convicto de que havia apenas perdido o trono, mas não o poder, nas eleições do ano 2000, ainda no rastro dos escândalos de seu terceiro mandato como prefeito, Belinati lança como candidato a vereador seu sobrinho, Marcelo Belinati Martins, pelo PSB, o qual obteve 1631 votos, quantidade insuficiente para a obtenção da vaga ou da suplência. Possivelmente a votação pequena (diante das grandes votações dos Belinati vereadores até então) tenha sido reflexo do processo ainda muito latente da cassação. A família sofre outra derrota nas eleições de 2002, quando Antonio Carlos Salles Belinati tenta a reeleição ao cargo de deputado estadual, agora pelo PSL, ficando apenas na suplência.

Em 2004, mesmo com a candidatura sob análise do TSE, Belinati disputa o cargo de prefeito de Londrina pelo PSL, obtendo 32,09\% dos votos válidos no primeiro turno, indo à disputa no segundo turno contra Nedson Micheletti, do PT, que obteve êxito na sua reeleição. Apesar da derrota, a ida ao segundo turno demonstra a força que Belinati ainda possuía em Londrina. A força do nome fica estampada neste 
pleito pela eleição massiva de Marcelo Belinati Martins, o qual obteve o primeiro lugar na eleição para vereador, também pelo PSL. Marcelo Belinati é filho de uma das irmãs de Antonio Belinati; é médico dos sistemas de atendimento móvel de urgência e emergência público (SIATE e SAMU) e atua também no setor privado de saúde, além de ser formado em Direito pela UEL.

As eleições de 2006 mostram mais uma vez a continuidade da força da família Belinati. Esta eleição é marcada por uma curiosidade, que ocorrerá novamente mais adiante: pai e filho disputando o mesmo cargo pelo mesmo partido - o PP, estratégia perfeita para o filho eleger-se às custas da votação expressiva do pai, o que quase aconteceu. Antonio Casemiro e Antonio Carlos pleitearam o cargo de deputado estadual, sendo que o patriarca Belinati elegeu-se com 81.571 votos; Antonio Carlos, apesar dos míseros 576 votos obtidos, ficou com a suplência. Emília Belinati , agora separada de Antonio Casemiro, disputa o cargo de deputada federal pelo antigo PFL, ficando também na suplência.

As eleições municipais de 2008, apesar de conturbadas, demonstram mais uma vez que Belinati retornou à política para ficar. Apesar de já ter reavido os direitos políticos, a sua candidatura estava sendo contestada no TSE em razão de contas não aprovadas pelo Tribunal de Contas, referentes ao seu terceiro mandato como prefeito. Mesmo diante do impasse da validade da candidatura, Belinati foi adiante, ainda que com poucos apoios políticos e partidários. Belinati disputou o segundo turno contra Hauly, numa batalha acirrada, elegendo-se com 51,73\% dos votos válidos. Menos de 48 horas após a sua eleição, em novembro de 2008, o TSE publicou a impugnação da sua candidatura, tornando assim inválido o pleito que acabara de ocorrer. Em 2010, com mais uma estratégia de sucesso, Belinati e seu filho Antonio Carlos, pelo PP, e a exesposa e matriarca da família, Emília Salles Belinati, pelo PSB, pleiteiam vaga na Assembleia Legislativa do Estado do Paraná. A estratégia aqui ficou por conta do nome: presume-se que, sabendo que possivelmente sua candidatura seria indeferida ou impugnada no TSE, Belinati registrou sua candidatura com o nome de Antonio Belinati, deixando o nome somente "Belinati" para o filho, possivelmente confundindo os eleitores sobre em quem estariam votando. Antonio Carlos ficou na suplência da vaga e em julho de 2013 assumiu vaga na ALEP, no lugar do deputado Fábio Camargo e deixou a vaga em janeiro de 2014, quando o deputado Osmar Bertoldi retornou à ALEP.

Antonio Carlos Salles Belinati é engenheiro civil; ocupou, no biênio 1997/1998, o cargo de diretor administrativo-financeiro da COMURB. Além de ter ocupado o cargo de deputado estadual entre os anos de 1999-2002, Antonio Carlos ocupou também, de 2011 até 2013, no atual governo de Beto Richa, o cargo de diretor comercial da SANEPAR, retornando para o cargo em janeiro de 2015 até os dias atuais.

Nas eleições municipais de 2012 Belinati, o patriarca, dedicou seu tempo e cedeu sua imagem para promover o seu sobrinho, o médico e vereador Marcelo Belinati Martins, que concorreu ao cargo de prefeito de Londrina pelo PP. Num processo eleitoral diferenciado, no qual não houve polarização entre dois partidos/candidatos, mas sim uma liderança absoluta de Marcelo Belinati nas pesquisas, Marcelo quase venceu o pleito no primeiro turno, obtendo 45,9\% dos votos válidos contra 25,27\% de Alexandre Kireeff, segundo colocado. No segundo turno, mesmo com o apoio da máquina do Governo do Estado e do seu tio, Marcelo perde para Kireeff, de forma muito disputada, sendo 48,14\% contra 47,12\% dos votos válidos. 
Apesar na derrota do sobrinho no executivo, nesta mesma eleição de 2012, Belinati fez mais um familiar campeão de votos no legislativo municipal. Marcos Roberto Guazzi Belinati é filho de José Belinati Filho; atuou na área técnica da Rádio Clube de Londrina, mas nunca chegou a ter programa radialístico. É formado em direito e atua como delegado de polícia, concursado, desde 1994. Antes de eleger-se vereador, Marcos Belinati estava atuando como Delegado Chefe da 11 a Subdivisão Policial, em Cornélio Procópio, cargo comissionado de confiança nomeado pelo Governador do Estado, Beto Richa, e pelo Secretário de Segurança Pública.

Ainda nas eleições de 2012, a família Belinati começa a dar sinais de que sua influência e força política vão para além dos limites de Londrina, uma vez que Antonieta Belinati Peres, irmã de Antonio Casemiro Belinati, elegeu-se vice-prefeita de Marialva em chapa composta com Edgar Silvestre, a qual obteve 57\% dos votos válidos no município. Antes, em 2004, Antonieta havia sido eleita para o cargo de vereadora, obtendo 626 votos. Em 2008 Antonieta reelegeu-se vereadora, sendo a segunda mais votada do município, com 926 votos. Ambas as eleições foram pelo PTB.

Nas eleições de 2014 a família obteve mais um êxito, alçando Marcelo Belinati ao cargo de deputado federal, pelo PP, sendo um dos mais votados do Estado do Paraná.

Além de todos os parentes que citamos até aqui, os quais ocuparam cargos eletivos ou comissionados importantes, foi possível localizarmos outros membros das famílias Belinati e Salles (de Emília Belinati) em cargos concursados ou de assessoramento, tanto no âmbito municipal quanto estadual: Simone Salles Belinati, a terceira filha de Antonio Casemiro e Emília, é servidora concursada da ALEP desde 1984; o único irmão de Belinati que não pleiteou cargo eletivo, Wanderley Belinati, também era funcionário administrativo concursado da ALEP, estando atualmente aposentado da função; na ALEP temos também o sobrinho de Emília Belinati, Edmilson Pinheiro Salles, que atuou como assessor no gabinete de Antonio Carlos Salles Belinati. Antes de trabalhar para o primo, Edmilson atuava no gabinete de Marcelo Belinati, na Câmara Municipal de Londrina. Na Câmara Municipal de Londrina atua também Suzelei de Fátima Guilherme Salles, esposa de Edmilson, como assessora no gabinete de Marcos Belinati. Outro parente da família, este irmão de Emília Belinati, Sebastião Salles Junior, trabalhou como assessor de Antonio Carlos Salles Belinati na ALEP na primeira vez em que ele foi deputado (1999-2002) e posteriormente atuou como assessor no gabinete do então vereador Marcelo Belinati.

Uma característica importante da família é que para além do nepotismo, o patriarca Antonio Belinati tem imenso poder de conseguir eleger os seus, sendo mais de vinte mandatos da família entre vereadores, prefeitos, deputados estaduais e federais, todos eles tendo sempre como principal capital político o sobrenome e a vinculação com o patriarca. Diferentemente de Antonio Belinati, a atual geração de "Belinatis" no poder preocupou-se em adquirir também capitais culturais e educacionais, sendo todos eles formados em nível superior em boas universidades e em profissões como médicos, advogados, engenheiros, etc. A aquisição destes capitais, muito possivelmente, só tenha sido possível graças ao capital político e econômico adquirido pela família até então, proporcionando aos seus filhos boas oportunidades. 
Antonio Casemiro, como já falamos antes neste trabalho, surgiu na política londrinense como um outsider e como todo recém-chegado, emprestando aqui as teses de Elias e Scotson (2000), pareceu apresentar uma ameaça à ordem política local, dominada até então pelos profissionais liberais de sucesso, associados ao agronegócio ou ao comércio/indústria. Porém, contrariando a tese, em alguns poucos anos, saiu da posição de outsider, consagrando-se hoje na condição de um estabelecido, com influência muito significativa na história política da cidade, agindo de forma coesa com a classe dominante local e até mesmo estadual, através de suas alianças. Belinati incorpou rapidamente o habitus da classe dominante local, passando a transitar dentro do campo social e político com tranquilidade, o que lhe permitiu inclusive destaque no cenário estadual no Paraná.

\section{Família Richa}

A família Richa tem uma passagem marcante pela cidade de Londrina, já que a carreira do seu precursor iniciou em Curitiba, no movimento estudantil, migrando para Londrina e retornando para a capital do Estado posteriormente, ocupando cargos nos Poderes Executivo e Legislativo. José Richa, o patriarca, apadrinhado politico de Ney Braga, nasceu no Estado do Rio de Janeiro e era filho de imigrantes. Foi líder estudantil e líder da Juventude Democrata Cristã - JDC. Seu primeiro cargo público foi no Departamento Odontológico de Curitiba; em 1961, atuou em cargo comissionado no governo estadual de Ney Braga, vindo a ocupar posteriormente a chefia de gabinete de Affonso Alves de Camargo Neto, então Secretário do Interior e Justiça. Foi Deputado Federal, eleito em 1962 pelo PDC. Após romper com Ney Braga, mudou-se para Londrina, onde estabeleceu relações com os cafeicultores locais. Em 1966 elegeu-se mais uma vez deputado federal. No bipartidarismo, filiou-se ao MDB e elegeu-se prefeito da cidade.

Em 1978, José Richa elegeu-se senador pelo MDB. Em 1982 elegeu-se Governador do Estado do Paraná. Antes de deixar discretamente a cena política, por "desencanto" segundo Arruda e Teixeira (2010), Richa foi eleito uma vez mais para o cargo de Senador, em 1986.

Richa foi casado com Arlete Richa, filha de um ex-Vereador de Jandaia do Sul, Vidal Vilela e bisneta de Manoel Gracia, que havia sido Prefeito de Irati. Arlete nunca ocupou cargos eletivos, detendo-se a cargos inerentes à cultura do primeiro-damismo. Com José Richa, Arlete teve três filhos: Carlos Alberto, José Richa Filho e Adriano. Sobre os demais membros da família Richa não iremos nos delongar, já que esse foi objeto de ampla pesquisa já publicada, de autoria do Professor Ricardo Costa de Oliveira, na obra "Na Teia do Nepotismo" (2012). Dos filhos de José Richa e Arlete Richa, o mais velho, José Richa Filho, conhecido como Pepe, engenheiro civil, foi assistente de direção na Secretaria de Estado de Transportes e Diretor Administrativo-Financeiro do Departamento de Estradas de Rodagem (DER), no governo de Jaime Lerner. Foi também Secretário Municipal de Administração de Curitiba na gestão municipal de seu irmão, Beto. Hoje é Secretário de Estado de Infraestrutura e Logística do Paraná, tendo sob seu domínio órgãos e serviços estratégicos como a Administração dos Portos de Paranaguá e Antoninia, o Departamento de Estradas de Rodagem, a Paraná Edificações e a Estradas de Ferro Paraná Oeste S.A. Pepe Richa é casado com Morgana Richa, a qual é juíza do Trabalho no Estado do Paraná e já foi membro do Conselho Nacional 
de Justiça. O filho mais novo de José e Arlete Richa, Adriano, formou-se em direito e atualmente, como relata Oliveira (2012), possui a titularidade do Cartório de Registro de Imóveis de Campina Grande do Sul.

Já o filho do meio, Beto Richa, foi aquele que a contragosto do pai, entrou "de cabeça" na política. Foi duas vezes deputado estadual, eleito em 1994 e 1998. No ano 2000, numa coligação com o PFL (atual DEM) e outras siglas menores, Beto é eleito vice-prefeito de Curitiba e acumulou o cargo de Secretário de Obras Públicas de Curitiba. Em 2002 Beto disputou as eleições para Governador do Estado do Paraná, ficando em terceiro lugar; em 2004 elegeu-se prefeito de Curutiba; em 2008, reelegeu-se. Atualmente é Governador do Estado do Paraná, em segundo mandato. Beto Richa é casado com Fernanda Bernardi Vieira Richa, herdeira daquela que já foi uma das maiores fortunas do Paraná. Neta de Avelino Antonio Vieira, um dos fundadores do Banco Bamerindus, prefeito do Município paranaense de Tomazina e deputado estadual pelo PSD, Fernanda também é bisneta de Manoel Eustáquio, Deputado Federal e Senador pelo Estado de Minas Gerais. A bisavó, Clara Xavier Araújo, era neta do Barão de Lavras. Beto e Fernanda têm três filhos: Marcello, André e Rodrigo. O primogênito, Marcello Bernardi Vieira Richa, ocupou o cargo de Secretário Municipal de Esportes, Lazer e Juventude de Curitiba, durante o governo de Luciano Ducci. Casou-se no ano de 2013 com a arquiteta Fernanda Risseti dos Santos, a qual, logo após a união com o filho do governador, foi nomeada para ocupar um cargo comissionado na $5^{\circ}$ Inspetoria do Tribunal de Contas do Estado do Paraná, a mesma de Ivan Bonilha, responsável pela fiscalização das contas de Beto Richa.

Em Londrina a família mantém-se no poder até os dias atuais com o jovem advogado Gustavo Corulli Richa, primo de Beto Richa, o qual se elegeu Vereador nas eleições de 2012. Outros dois primos de Beto Richa que fazem parte de sua "teia de nepotismo" são Marcos Elias Traad da Silva e Luiz Abi Antoun. Traad foi presidente da CODAPAR, diretor do Polo Regional de Pesquisa do IAPAR e integrante do Grupo de Planejamento do SIMEPAR, todos cargos em órgãos da administração estadual. Apesar de ser doutor em zootecnia, desde o ano de 2011, ocupa o cargo de Diretor-Geral do DETRAN-PR, nomeado pelo primo Beto. O outro primo, Luiz Abi Antoun, conforme relata Oliveira (2012), foi Assessor Parlamentar de Beto Richa na ALEP, estando sempre como fiel escudeiro de Beto. Atualmente não ocupa nenhum cargo comissionado no Governo do Estado, mas é tido com um dos homens mais importantes para se chegar até Beto Richa e está envolvido em uma série de escândalos amplamente divulgados na imprensa do Paraná.

\section{Família Dias}

Outros dois expoentes da política do Norte do Paraná, especificamente de Londrina e Maringá, são os irmãos Álvaro Fernandes Dias e Osmar Fernandes Dias, latifundiários, oriundos de Quatá, Estado do São Paulo. Álvaro Dias, historiador, líder do movimento estudantil na UEL, foi o vereador mais jovens a elegerse em Londrina, em 1968. Em 1970, elegeu-se deputado estadual; em 1974 elegeu-se deputado federal; em 1982 elegeu-se pela primeira vez Senador. Em 1986 renunciou ao cargo para disputar o Governado do Estado do Paraná, eleito pelo PMDB. Em 1994, disputou o cargo de Governador do Estado novamente, agora pelo PP, mas não saiu vitorioso. Em 1996 foi presidente da extinta TELEPAR. Em 1998 elegeu-se senador novamente, cargo que vem reelegendo-se sucessivamente até os dias atuais. Álvaro é casado com a 
advogada Débora Amaral de Almeida Fernandes Dias, com quem tem um casal de filhos: Carolina de Almeida Dias e Álvaro Dias Filho. Débora é filha de João Amaral de Almeida, ex-Procurador do Município de Curitiba, presidente do Instituto Municipal de Administração Pública - IMAP na década de 1970 e assessor parlamentar. Conforme Oliveira (2012), Carolina Dias, filha de Álvaro e Débora, casou-se com o neto do ex-governador Ney Braga, Pedro Braga Maia, com quem tem um filho, herdeiro, neto e bisneto de duas das principais figuras da história política do Paraná.

Osmar Fernandes Dias, engenheiro agrônomo, iniciou sua carreira política pelos braços do nepotismo, tendo ocupado seu primeiro cargo como Presidente da Companhia Agropecuária de Fomento Econômico do Estado do Paraná. Foi Secretário de Estado de Agricultura e Abastecimento do Paraná. Em 1994 elegeu-se senador, reeleito em 2002. Desde 2010 ocupa a vice-presidência de Agronegócios e Micro e Pequenas Empresas, no Banco do Brasil, sendo considerado um dos "homens" de Dilma Roussef, atual Presidente da República, no Estado do Paraná.

\section{Família Hosken de Novaes}

José Hosken de Novaes se destacou como profissional liberal na advocacia, o que lhe valeu a nomeação ao seu primeiro cargo público, o de Procurador Jurídico do Município de Londrina, em 1951. Em 1955 foi eleito vereador, mas não assumiu ao cargo para atender ao convite de Bento Munhoz para assumir a Procudoria-Geral do Estado do Paraná. Ocupou, em 1955, o cargo de Secretário de Estado da Fazenda, cargo que deixou para disputar ao cargo de prefeito de Londrina, tendo sido eleito. Foi nomeado vice-governador do Estado, assumido o cargo de governador de 14/05/1982 a 15/03/1983. Hosken era casado com Adelina Castaldi, a qual foi nomeada para o cargo de chefe do Departamento de Educação e Assistência Social de Londrina quando o marido era prefeito. Antes disso, Rubens Castaldi (irmão de Adelina) também havia sido secretário municipal. Após ter sido governador, Hosken e a família deixaram a política, tendo ele seguido na carreira de advogado.

\section{Família Rocha Loures}

Como esta família é extensa e seus membros ocuparam cargos em diversas cidades do Paraná, nos ateremos apenas àqueles que atuaram em Londrina. A família Rocha Loures tem como principal precursor na área da política no Estado do Paraná o advogado João Alves da Rocha Loures, mas em Londrina, Josino Alves da Rocha Loures, irmão de João, foi uma das figuras fundamentais no processo de formação política da cidade. Josino, medico, foi o proprietário do primeiro jornal impresso da cidade, o qual foi utilizado abertamente para fins politicos. Foi vereador em Joinville e em 1947 foi eleito também vereador em Londrina, reeleito em 1951. Foi chefe do Departamento de Assistência Técnica aos Municípios do Estado do Paraná, deputado federal e Secretário de Estado do Trabalho e Assistência Social.

Outro Rocha Loures na política londrinense, Renato Loures Bueno, nascido em Palmas, médico, elegeu-se vereador em 1955; foi eleito deputado estadual em 1958; em 1959 disputou a 
Prefeitura de Londrina, sendo derrotado. Elegeu-se deputado estadual por mais duas vezes (1963 e 1967). Mudou-se para Cascavel onde ocupou os cargos de Diretor Clínico do Centro de Pesquisas Médicas e Secretário Municipal da Saúde e Assistência Social. Em 1976 foi Ministro Substituto do Tribunal de Contas do Paraná e em 1978 elegeu-se novamente deputado estadual. Em 1983 foi eleito deputado federal. Após este período, a família Rocha Loures mudou seu foco para a capital do Estado do Paraná, tendo com principais expoentes Rodrigo e Rodriguinho da Rocha Loures (filho e neto de João de Alves da Rocha Loures, respectivamente). A parte da família que permaneceu em Londrina exercem atividades de tabelionato (Cartório Salinet e Cartório Rocha)

\section{Família Carvalho Canizares}

A família Carvalho tem como principal expoente Gilberto Carvalho, político que, embora nunca tenha tido sucesso em cargos eletivos, exerceu por mais de doze anos, entre os governos do presidente Lula e de Dilma Roussef, ambos do PT, o posto de um dos homens mais importantes de articulação política e institucional do Governo Federal. Sua trajetória profissional o levou até o ABC paulista, onde trabalhou na indústria metalúrgica e engajou-se ao grupo de Lula. Foi Secretário de Governo de Santo André em 1997. O posto de "melhor amigo de Lula" rendeu-lhe, além de cargos comissionados, poder e influência no Governo Federal, já que é tido como conselheiro de Lula e homem de livre acesso pelo gabinete da Presidência da República. Ocupou o cargo de Chefe de Gabinete da Presidência da República entre 2003 e 2010; em 2011, Gilberto Carvalho foi elevado ao posto de Ministro-Chefe, assumindo a Secretaria Geral da Presidência da República. No início de 2015, deixou o cargo de Ministro, mas foi prontamente alocado na presidência do Conselho Nacional do SESI - Serviço Social da Indústria. A influência de Gilberto Carvalho levou sua irmã, Márcia Helena Carvalho Lopes, ao cargo de Ministra do Desenvolvimento Social e Combate à Fome. Doutora em Serviço Social, Márcia também foi vereadora e Secretária Municipal de Assistência Social de Londrina. Atualmente atua no Instituto Lula. A família ainda possui mais um membro na política londrinense, Rubens Canizares, primo de Márcia e Gilberto por parte de mãe (família Ballarotte). Engenheiro civil e empresário do ramo da construção civil, Rubens ocupou a Presidência da AMA em Londrina; em 2000 elegeu-se vereador em Londrina; seis meses após a posse, assumiu a Diretoria Técnica da agora extinta FUNDEPAR, cargo de nomeação estadual.

\section{Família Corrêa/Correia}

Manoel Jacinto Corrêa foi o primeiro político de esquerda, comunista, a ocupar um cargo público em Londrina, eleito vereador em 1947. Apesar deste ter sido o único cargo eletivo ocupado, a atuação política de Manoel Jacinto foi mais marcante nas disputas dos trabalhadores pelas terras devolutas, tendo sido um dos protagonistas da chamada "Revolta do Quebra Milho" ou "Batalha de Porecatu". Atuou também na fundação de vários sindicatos, a maioria de trabalhadores rurais. Manoel é pai de Elza Pereira Correia, historiadora, 
docente da UEL; foi vereadora por vários mandatos em Londrina, deputada estadal e secretária de estado no governo de Roberto Requião.

\section{Família Janene/Jannani/Jenani}

A família Janene sempre esteve em evidência na mídia, infelizmente ligada a fatos não tão lícitos, sendo citado o seu envolvimento em casos de corrupção envolvendo o antigo banco público do Paraná, o BANESTADO, o caso AMA/COMURB já relatado neste trabalho, o mensalão e agora, na mais recente operação da Polícia Federal, conhecida como Lava-Jato ${ }^{6}$. A família possui três grafias do sobrenome: Janene, Jannani e Jenani. Abdelkarim Janene e o filho Jamil Janene, pecuaristas criadores de gado nelore, vieram do interior de São Paulo. Jamil (mais tarde teremos outro familiar de nome homônimo), foi presidente da Sociedade Rural do Paraná por dois mandatos consecutivos (1980-1982 e 1983-1984). O membro mais famoso da família é José Mohamed Janene, filho de imigrantes libaneses; foi um dos principais articuladores políticos de Belinati, e posteriormente, um dos principais articuladores nacionais do PT e PP. Foi deputado federal por três vezes, pedindo aposentadoria da Câmara no último mandato para livrar-se de uma possível cassação devido à processo que respondia. Parceiro de "trabalho" e da vida, Janene tinha como fiel escudeiro o doleiro Alberto Youssef, com quem mantinha uma relação de compadrio, tendo Youssef batizado o filho caçula de Janene.

Assad Jannani (PDT), irmão de José Janene, foi vice-prefeito de Londrina, na gestão de Luiz Eduardo Cheida (PT), acumulando o cargo de presidente da SERCOMTEL. Na segunda gestão de Belinati, Assad foi Secretário Muncipal de Serviços Públicos, secretaria responsável pelas articulações, contratações e concessões de transporte público, coleta de resíduos sólidos, dentre outros. Durante este período, o outro irmão de José Janene, Faiçal Jannani, prestou uma série de serviços ao município de Londrina com as empresas Visatec, Visacon e Visamáquinas. No terceiro mandato de Belinati, Assad assumiu a presidência da COHAB/LD; também foi chefe de gabinete de Barbosa Neto, ex-prefeito de Londrina, na primeira vez em que este foi deputado estadual.

Outro membro na política é Jamil Jenene (homônimo de seu parente já citado aqui), sobrinho de José Janene. Foi eleito vereador três vezes em Londrina. Para além dos nomes e cargos aqui já citados, é possível encontrar alguns outros parentes de José Janene ocupando cargos mais coadjuvantes, tais como Dulcinéia Jannani, esposa de Assad Jannani, que ocupou cargo comissionado na ALEP durante o mandato de Barbosa Neto, ocasião em que foi acusada de ser funcionária fantasma daquela casa legislativa ${ }^{7}$ Mehedin Hussein Jenani, primo de José Janene, e sua esposa, Rosa Alice Valente, ocuparam cargos comissionados na Assessoria Parlamentar de José Janene em Brasília. Uma das irmãs Janene, Soleima Janene Barion, também

6 Como Londrina virou o tubo de ensaio que inventou o petrolão. Disponível em <http://www.gazetadopovo.com.br/vida-publica/como-londrina-virou-o-tubo-de-ensaio-que-inventou-o-petrolaodw4t01v0kn0gk7u3049vz52kb?ref=capa-gg>. Acesso em 28 fev. 2014.

\footnotetext{
${ }^{7}$ Esposa de Assad faria assessoria para Barbosa "em casa". Disponível em <http://www.bonde.com.br/?id_bonde=1-3-786-20090630.> Acesso em 01 mar. 2015.
} 
esteve envolvida nos negócios de José, sendo que ela e o esposo, Jurandir Barion, foram sócios investidores de José Janene na empresa de iluminação Eletrojan, a qual manteve contratos com uma série de municípios do Estado do Paraná.

O poderio da família Janene também se estendeu às duas principais organizações de Londrina: Sociedade Rural do Paraná - SRP e Associação Comercial e Industrial de Londrina - ACIL. Na ACIL foi Assad Jannani que representou a família, ocupando uma diretoria. O mesmo Jamil Janene citado no início deste item, além de presidente da SRP, ocupou também uma série de cargos de diretoria e nos conselhos deliberativos. O pai de Jamil, Abdelkarim Janene, foi conselheiro, membro suplente da Comissão Fiscal, membro do Conselho Deliberativo da SRP. Inocêncio Janene foi Diretor do Departamento Social. O membro mais contemporâneo da ala da família Janene vinculada ao agrobusiness, é o agropecuarista Marcelo Janene El Kadre, Diretor de Atividades Agrícolas, de Pecuária e Diretor Vice-Presidente da SRP.

Com fama de mandão, centralizador e obcecado pelo poder e dinheiro, o personagem central da família, José Janene, levou consigo do ápice à derrocada um sem fim de parentes, já citados aqui, além de outros políticos. Em entrevista ao Jornal de Londrina, em 02 de março de 2015, o promotor londrinense Claudio Esteves, que investigou Janene em vários dos casos em que esteve envolvido relata: "Ele se impunha pelo poder, pelo jeito de agir e era arrojado quando desviava dinheiro. Quem queria enriquecer se aproximava dele e ficava sob o guarda-chuva dele". ${ }^{8} \mathrm{Na}$ mesma reportagem, sua ex-esposa, Stael, descreve em poucas palavras José Janene: "O Zé era assim: me ame ou me odeie".

\section{Família Del Ciel}

O principal membro da família Del Ciel é José Antonio Del Ciel, advogado, agropecuarista; foi vereador por duas legislaturas em Londrina e vice-prefeito, assumindo mandato quando Belinati desecompatibilizou-se do cargo para fins eleitorais; foi também deputado estadual. O pai de Del Ciel, José Del Ciel Filho, fora vereador em Ourinhos-SP, chegando a presidente da Câmara de Vereadores. Em 1959, José Del Ciel Filho ocupou o cargo de prefeito da cidade (Ourinhos), quando o titular do cargo desincompatibilizou-se para concorrer a outro cargo. Outro membro da família na política foi o irmão de José Antonio, José Luiz Del Ciel, o qual elegeu-se vereador em Londrina, chegando a ser Presidente da Câmara de Vereadores, tendo assumido por alguns períodos a Prefeitura da cidade. Na gestão de viceprefeito, José Antonio Del Ciel valeu-se do nepotismo, indicando para o cargo de Presidente da Companhia de Desenvolvimento de Londrina - CODEL o seu concunhado, Lauro Pepiliasco, engenheiro civil e empresário do ramo da construção, casado com Vanda de Souza Pepiliasco, irmã de Lucy de Souza Del Ciel (ex-esposa de José Antonio).

\footnotetext{
8 Janene sempre perto do poder. Disponível em $<$ http://www.jornaldelondrina.com.br/londrina/conteudo.phtml?tl=1\&id=1534528\&tit=Janene-sempre-esteve-perto-dopoder.> Acesso em 02 mar. 2015.
} 


\section{Família Gabardo}

O principal personagem na política londrinense é João Olivir Gabardo, conhecido apenas como Olivir Gabardo; formado em direito e licenciado em geografia e história; fazia parte de um grupo de jovens advogados e profissionais liberais engajados no movimento político em Londrina. Além de advogado, Olivir também era professor universitário e chegou a ser diretor da Faculdade de Filosofia, Ciência e Letras de Londrina. Liderança do MDB local, Gabardo teve fundamental importância na política londrinense, pois nas fileiras da universidde recrutou alguns daqueles que hoje protagonizam a política paranaense, tal como Álvaro Dias. Foi vereador em Londrina; deputado estadual e líder do MDB na ALEP; deputado federal por três legislaturas e vice-líder do MDB na Câmara Federal; foi nomeado por José Richa para o cargo de Conselheiro do Tribunal de Contas do Paraná, chegando a ser presidente daquele órgão; na primeira gestão de Requião no Governo do Paraná, Olivir foi Secretário Especial da Ouvidoria Geral e Secretário de Estado de Educação quando Mário Pereira assumiu ao governo; sua última incursão política foi como suplente de Senador, assumindo a vaga quando Álvaro Dias licenciou-se para concorrer ao Governo do Paraná. Outro membro da família foi Ezenir Gabardo, a qual ocupo o cargo de Diretora-Geral da Secretaria de Estado de Educação e, posteriormente, da Secretaria de Estado do Trabalho e da Ação Social, nos governos de Álvaro Dias e Requião, respectivamente. Nos registros da história de Londrina, encontramos ainda dois outros membros da família Gabardo, são os primos Arthur e Omar Gabardo. Arthur Gabardo, ocupou o cargo de Secretário Geral de Londrina entre 1941 e 1943, na equipe do também curitibano e prefeito nomeado de Londrina, Capitão Miguel Balbino Blasi. O outro, mais contemporâneo, Omar Gabardo, ocupou o importante cargo de Secretário Municipal da Fazenda na gestão de Wilson Moreira.

\section{Família Leite Chaves}

Os irmãos Leite Chaves, Jonas e Francisco, vieram do Estado da Paraíba na década de 1970 para Londrina. Jonas Leite Chaves, engenheiro agrícola, foi quatro vezes deputado estadual no seu Estado natal, chegando a ocupar a presidência da Assembleia Legislativa da Paraíba. Francisco Leite Chaves, doutor em direito pela UNB, como tantos outros jovens advogados de sucesso, mudou-se para Londrina pensando que as batalhas pela posse das ricas terras vermelhas, ainda em fase de ocupação e expansão, pudessem lhe render boas causas e, por consequência, dinheiro; construiu o primeiro shoping center de Londrina. Interessado em política, procurou o MDB estadual na tentativa de candidatar-se a deputado federal, mas lhe foi oferecida a candidatura ao Senado, a qual era muito improvável, já que era um desconhecido no Paraná. Nesse contexto, após muito caminhar pelo Paraná, numa campanha repleta de histórias míticas e místicas, as quais estão amplamanete relatadas no livro de Sylvio Sebastiani, "Por dentro do MDB Paraná", Leite Chaves foi eleito Senador, com forte atuação de Belinati e Álvaro Dias na campanha, então políticos emergentes. A aliança entre Belinati e os irmãos Leite Chaves foi duradoura. Quando eleito Prefeito de Londrina pela primeira vez, Belinati nomeou Jonas Leite Chaves para o cargo de Secretário Municipal de Fazenda de Londrina. Leite Chaves ainda foi eleito suplente de Senador, assumindo a vaga quando Álvaro Dias deixou o 
senado para assumir ao Governo do Estado do Paraná; posteriormente, foi nomeado no cargo de ProcuradorGeral da Justiça Militar.

Embora hoje aposentado, Leite Chaves, ainda possui um escritório de advocacia no Distrito Federal e mantém negócios no Paraná. Seu filho, advogado londrinense renomado, Rogério Marinho Leite Chaves, já ocupou vários cargos públicos: Procurador do Banco Central, Defensor Público (concursado) e Procurador do Distrito Federal, também através de concurso, função a qual detém até os dias atuais. Em 2011 assumiu a Procuradoria-Geral do Distrito Federal, mas deixou o cargo no final de 2012, segundo a imprensa, por discordar da forma de atuação do então governador do Distrito Federal, Agnelo Queiroz?

\section{Família Maculan}

O principal membro desta família com atuação em Londrina foi Nelson Maculan; comerciante de veículos e máquinas agrícolas, proprietário de terras na região de Londrina, vinculado à Sociedade Rural do Paraná, na qual ocupou a presidência e vários outros cargos de diretoria. Sua circulação pelo grupo dominante na política local lhe rendeu uma cadeira na Câmara de Vereadores de Londrina, a qual acumulou com a presidência da SRP. Na presidência da SRP Maculan teve um papel fundamental no movimento chamado "Marcha da Produção". Sua atuação em defesa da agricultura e do que hoje chamamos de agronegócio acabou aproximando-o de Abilon de Souza Naves, político da capital do Paraná, cotado para ser o próximo Senador e Governador do Estado. Dessa aproximação entre Souza Naves e Maculan, entre capital político e capital econômico (cafeeiro), saiu a chapa para concorrer ao Senado Federal em 1958, pelo PTB, na qual Souza Naves foi o vencedor como titular, com Maculan na suplência; a morte de Souza Naves levou Maculan a assumir a titularidade da vaga no Senado. Maculan também ocupou vários cargos de primeiro e segundo escalão no extindo Instituto Brasieliro do Café - IBC. Antes de voltar para o Rio de Janeiro, sua última incursão na política foi o cargo de deputado federal pelo Paraná. O filho mais velho de Maculan, Nelson Maculan Filho, engenheiro de minas e metalurgia, foi reitor da Universidade Federal do Rio de Janeiro, Secretário Nacional de Ensino Superior durante o governo Lula, Secretário de Estado de Educação no Rio de Janeiro e atualmente é Professor Emérito da UFRJ.

\section{Família Cesário Pereira}

Esta família tem como principal membro Otávio Cesário Pereira Junior, conhecido no meio político como "Jaburu". Advogado, líder estudantil, iniciou a carreira como Procurador Jurídico da Prefeitura de Cambé, cidade vizinha de Londrina. Cesário aliou-se ao grupo da UDN vinculado à Ney Braga e posteriormente à ARENA, o que lhe rendeu a nomeação para Secretário de Estado do Trabalho e Assistência Social, acumulado com o cargo de Secretário Interino de Estado de Saúde Pública, no governo de Ney Braga. Quando Ney Braga assumiu ao Ministério da Agricultura, Cesário foi seu chefe de gabinete em

9 Patrono da Ética, Rogério Leite Chaves deixa equipe de Agnelo Queiroz. Disponível em <http://informandoedetonando.blogspot.com.br/2012/04/patrono-da-etica-rogerio-leite-chaves.html.>. Acesso em 12 fev. 2015. 
Brasília. Foi eleito suplente de deputado federal duas vezes e nas duas acabou assumindo a vaga antes do final da legislatura. Elegeu-se suplente de Senador junto com Ney Braga e assumiu a titularidade quando Ney assumiu ao Ministério da Educação. Ocupou vários cargos dentro da SRP. Quando Jayme Canet foi eleito Governador do Paraná pela ALEP, Cesário foi indicado como vice-governador, assumindo esporadicamente ao governo na ausência do titutar. No segundo governo de Ney Braga no executivo estadual, assumiu o cargo de Secretário de Estado da Justiça. Sua última incursão política foi a eleição no cargo de deputado federal. Como herança de seu capital político, Cesário Junior deixou para o filho mais velho, Otávio Cesário Neto, o "Vico", duas concessões de cartório em Londrina, uma de rádio FM em Londrina e outra AM em Cambé. Cesário Neto também ocupou vários cargos na Sociedade Rural do Paraná, já que também atua no agronegócio. Cesário Pereira era primo de Mário Pereira, o qual foi Vice-Governador do Paraná no início dos anos de 1990 e Governador do Paraná em 1994. Em entrevista à Faria e Sebastiani (1997), Cesário Pereira é enfático em dizer que apesar de primos, ele e Mário não mantinham qualquer tipo de relação de afinidade ou de interesse, sendo inclusive opositores no campo da política.

\section{Família Stamm}

Mário Cesar Stamm, engenheiro civil, servidor público do Departamento de Estradas de Rodagem DER. Durante o governo municipal de Hosken de Novaes, foi membro do Conselho de Planejamento Industrial de Londrina - COPIL. A serviço do DER, assumiu a chefia do $7^{\circ}$ Distrito Rodoviário de Londrina (cargo de nomeação estadual). Foi Diretor Geral do DER, a convite de Paulo Pimentel. Da diretoria do DER saiu para assumir cadeira na Câmara Federal. Embora não tenha tido tanto sucesso em cargos eletivos (foi derrotado três vezes nas eleições para Prefeito de Londrina), Stamm acabou compartilhando com os filhos seu capital, sendo dois deles advogados e um engenheiro, como o pai, da área de transportes. Mário Cesar Stamm Junior, doutor na área de engenharia de transportes, é professor da UEL; foi presidente do Instituto de Pesquisa e Planejamento Urbano de Londrina - IPPUL, chefe adjunto da Coordenação da Região Metropolitana de Curitiba - COMEC, Secretário de Estado de Desenvolvimento Urbano e Secretário de Estado dos Transportes. O outro filho de Mário Stamm, Marcos Vitório Stamm, advogado de carreira do Governo do Estado do Paraná, foi assessor na Casa Civil do Poder Executivo Estadual, Diretor Geral da Secretaria de Estado do Emprego e Relações do Trabalho e desde 2012 é presidente da Associação Brasileira dos Advogados Públicos - ABRAP. O terceiro filho de Mário Stamm, Marcio Fernando Stamm, é atualmente Chefe de Gabinete do prefeito de Londrina, Alexandre Lopes Kireff.

\section{Família Scaff}

A família Scaff possui uma história bastante peculiar na cidade. A história política da família em Londrina perpassa, principalmente, pelos irmãos Jacy, João e Jorge Scaff. Jacy Scaff tem sua história vinculada à prática de algumas contravenções, mais especificamente ao chamado "jogo do bicho". O blog "Doc Londrina" publicou recentemente um compilado de uma série de jornais das décadas de 1950 e 1970 , 
chamando-o de "A História do Jogo do Bicho em Londrina-PR ${ }^{10 ", ~ g r a n d e ~ p a r t e ~ d e l a s ~ e n v o l v e n d o ~ J a c y, ~ o ~}$ qual entrou no "negócio" por ter se casado com a filha do dono da banca de jogo do bicho mais famosa de Londrina, a Banca Ferradura, a qual herdou do sogro. Começou a relacionar-se com a classe dominante devido aos jogos de azar, já que grande parte dos membros da classe política da cidade frequentavam suas casas de jogos de azar. Foi também presidente do Londrina Esporte Clube, time oficial da cidade. O irmão de Jacy, Jorge Scaff, era fiscal da Receita Federal em Londrina. Jorge Scaff também era ligado ao futebol; além de ter sido ele mesmo jogador, foi também técnico do Londrina Esporte Clube por quatro vezes, membro da comissão técnica do Clube Atlético Paranaense, além de ter presidido um dos maiores clubes sociais da cidade, o Grêmio Recreativo Londrinense. Jorge foi eleito vereador em Londrina por dois mandatos e sua imagem é fortemente ligada à construção do chamado Estádio do Café, que tem como nome oficial "Estádio Jacy Scaff" e sua construção é no formato de uma ferradura. O estádio foi construído na gestão municipal de José Richa, amigo pessoal de Jacy Scaff. Jorge também foi prefeito interino de Londrina, quando da cassação de Antonio Belinati, pois era Presidente da Câmara de Veradores. O terceiro irmão, João Scaff, foi eleito suplente de vereador em Londrina, efetivado durante o mandato. Outro membro da família é Roberto Ávila Scaff (Beto Scaff), filho de Jacy, o qual foi eleito verador; Beto também é ligado ao futebol, chegando também a presidir o Londrina Esporte Clube.

\section{Família Canziani}

A família Canziani se junta a mais uma daquelas em que poder político e cartórios estão atrelados. Severo Rudin Canziani era funcionário público estadual e foi nomeado pelo então Interventor do Estado, Manoel Ribas, como Coletor Estadual em Londrina, recebendo mais tarde de Moyses Lupion a nomeação como Oficial do Registro de Imóveis, Títulos e Documentos do $2^{\circ}$ Registro da Comarca de Londrina. O herdeiro político de Severo Canziani é seu neto, Alex Canziani da Silveira. Com sólida carreira política, já foi vereador, deputado estadual e cinco vezes deputado federal. Foi presidente da CODEL e vice-prefeito, cargo ao qual renunciou para assumir vaga na Câmara Federal. Foi também Secretário de Estado do Emprego e Relações do Trabalho.

\section{Família Caldarelli}

A Família Caldarelli obteve sucesso político em cargos eletivos apenas com o pai, Oswaldo Caldarelli, funcionário público estadual, vereador em Londrina por cinco mandatos consecutivos. Assim como a família Scaff, os Caldarelli também estão diretamente ligados ao Londrina Esporte Clube, sendo Oswaldo um dos entusiastas da fundação oficial do time próprio de Londrina. Ele próprio e um dos filhos, Marcelo, já foram dirigentes do time de futebol. Todos os filhos de Oswaldo tiveram incursão na política, mas nenhum obteve sucesso nos pleitos que disputaram. O mais conhecido dos quatro filhos é Rubens Luiz Caldarelli, o qual tem sua história e imagem muito vinculada ao apresentador de televisão e radialista Luiz

\footnotetext{
${ }^{10}$ A história do jogo do bicho em Londrina. Disponível em <http://doclondrina.blogspot.com.br/2012/11/a-historia-dojogo-do-bicho-em-londrina.html>. Acesso em 26 mar. 2014.
} 
Carlos Alborgueti, o lendário "Cadeia", tendo sido assessor de gabinete dele na ALEP. Caldarelli não ocupa cargos públicos formalmente, mas está sempre na articulação. Prova dessa função de articulador local é que nas poucas visitas à Londrina feitas pelo atual governador do Paraná, Beto Richa, Rubens Caldarelli foi fotografado e filmado ao lado de Beto nas imagens publicadas. Em dezembro de 2014, quando Beto Richa transferiu a sede do Governo do Estado por um dia para Londrina, Caldarelli agrediu com um guarda-chuva uma estudante da UEL que protestava contra o governo de Richa. No sítio eletrônico de transparência do Governo do Estado do Paraná, o filho de Rubens, Rubens Luiz Caldarelli Filho figura como ocupante de um cargo comissionado na Secretaria de Estado de Segurança Pública. Irmão de Rubens, Ângelo Marcelo Caldarelli foi também presidente do Londrina Esporte Clube. Mauro Caldarelli e José Eduardo Caldarelli, também filhos de Oswaldo Caldarelli, disputaram eleições para vereador em Londrina, não tendo sucesso no pleito.

Diante do até aqui exposto, podemos concluir que diferentemente do imaginário criado em relação ao Norte do Paraná no qual se acreditava que dali surgiria uma modernização na política, uma renovação através de práticas desvinculadas dos grupos do Paraná Tradicional, distantes do familismo, do clientelismo, do paternalismo e da patronagem, viu-se ao longos das últimas décadas ocorrer o contrário: as novas forças políticas surgidas no Norte do Paraná, junto com seus grupos familiares, associaram-se aos grupos dominantes tradicionais do Estado e, atualmente, passaram a tomar frente da elite política estadual, com importante influência até no cenário nacional, demonstrando assim que o tempo não é um fator determinante para a construção das relações de poder e parentesco, reafirmando a tese de Oliveira (2012) de que onde há instituições e poder haverão relações familiares envolvidas, já que este é um fenômeno intrínseco à política brasileira.

\section{REFERÊNCIAS}

ARRUDA, Rose; TEIXEIRA, Hélio. Richa: o político. Curitiba: Independente, 2010.

BOURIDEU, Pierre. Razões Práticas: Sobre a teoria da ação. 11ed. Campinas/SP: Papirus, 2011.

. A economia das trocas simbólicas. 7.ed. São Paulo/SP: Perspectiva, 2011 b.

CERVI, Emerson Urizzi. Rádio e Renovação Política em Eleições Majoritárias: As vitórias eleitorais de prefeitos/radialistas em Londrina e Ponta Grossa. Dissertação de Mestrado. 2002. UEPG.

CESÁRIO, Ana Cleide Chiarotti. Poder e partidos políticos em uma cidade média brasileira: um estudo de poder local: Londrina-PR, 1934 - 1979.

COSTA, Osmani Ferreira. Rádio e política: a aventura eleitoral dos radialista no século XX. Londrina/PR: Eduel, 2005. 
ELIAS, Norbert.; SCOTSON, John L. Os estabelecidos e os outsiders. Trad. Vera Ribeiro. Zahar: Rio de Janeiro, 2000.

FARIA, Enéias e SEBASTIANI, Silvio. Governadores do Paraná: A história por quem construiu a história. Curitiba: Sistani, 1997.

FERREIRA, João Carlos Vicente. O Paraná e seus municípios. Cuiabá: J.C.V. Ferreira, 1999.

MONTAGNER, Miguel Ângelo. Trajetórias e biografias: notas para uma análise bourdieusiana. Revista Sociologias, Porto Alegre, ano 9, n.17, p. 240-264, jan/jun.2007.

OLIVEIRA, Ricardo Costa de. Na teia do nepostismo: sociologia política das relações de parentesco e poder político no Paraná e no Brasil. Curitiba: Insight, 2012.

SEBASTIANI, Sylvio. Por dentro do MDB Paraná. Revista Nova Fase: Curitiba, 1992.

TOMAZI, Nelson Dacio. Norte do Paraná: história e fantasmagorias. Tese de Doutorado. UFPR. Curitiba, Fevereiro, 1997.

\title{
POLITICAL POWER AND RELATIONSHIP OF RELATIONS IN LONDRINA -PARANÁ
}

\begin{abstract}
Nepotism is latent phenomena in brazilian politics, happening both in the older and more tradicional regions and places where the colonization is recent, which is the case of the city of Londrina, Paraná state, wherein, in only 80 years of history, political power and kinship networks have already been established. The object of this work are the relations between political power and kinship created in Londrina, aiming to verify if these relations also happen in newer cities that don't belong to the so called "Traditional Paraná", in which it was shown that time, in this case, isn't a determinant factor to the creation of the nepotism network, but the existence of political and economical capital and also relations that guarantee social capital to begin a political career, to maintain and to propagate it, keeping their relatives in the brazilian political scenario is. Besides, the placement of relatives in strategic posts is a way to guarantee that power has longevity, because this way there's control of the institutions that are responsible for tracking the actions of the state and the government. In Londrina we have an expressive family, being the biggest group that still has local power, even spreading to other powers and government levels. This is the Belinati family, that started its political activites with Antonio Casemiro Belinati, an outsider politician that over the course of his history became an established politician; the Belinati group has more than fifteen member of the family that together already have held more than forty public positions, elective, comissioned or permanent. Besides this central family, we also studied other sixteen families involved in the politics of the city, many of them with recognition both in this state and in the whole country. These are: Richa, Dias, Hosken de Novaes/Castaldi, Rocha Loures, Carvalho/Canizares, Corrêa, Janene/Jannani/Jenani, Del Ciel, Gabardo, Leite Chaves, Maculan, Cesáreo Pereira, Stamm, Scaff, Canziani and Caldarelli families. We used the biography sociology as the research method, analysing the trajectory of these families, verifying their actions in a social space, using the categories of field, habitus and capital, created by Pierre Bourdieu.
\end{abstract}

Keywords: Nepotism. Political Power. Families. Londrina-Paraná. 